\title{
LESÕES PRECURSORAS DO CÂNCER CERVICOUTERINO: EVOLUÇÃOO HISTÓRICA E SUBSÍDIOS PARA CONSULTA DE ENFERMAGEM GINECOLÓGICAa
}

\author{
Cervical-uterine cancer precursor lesions: historical evolution supporting the \\ gynecological nursing consultation \\ Lesiones precursoras del cáncer cervical-útero: evolución histórica consolidando la \\ consulta de enfermería ginecológica
}

Maria Cristina de Melo Pessanha Carvalho ${ }^{1}$

Ana Beatriz Azevedo Queiroz ${ }^{2}$

\begin{abstract}
RESUMO
Estudo emergido de recorte de dissertação de mestrado, ilustrando a evolução histórica das lesões precursoras do câncer cervicouterino (LPCCU). Trata-se da história das LPCCU, delineando a relevância do conhecimento para prática do enfermeiro na área da saúde da mulher. 0 conceito de LPCCU inicia-se a partir do século XIX, dando início aos estudos das células alteradas. Objetivo: descrever as diversas fases da evolução histórica das alterações cervicais. Estudo qualitativo, descritivo-analítico, recorte temporal no período de 1940 a 2008. Dados levantados mediante bibliografia de fonte primária e recurso BIREME. Pontuaram-se as classificações que já existiram, destacando a Nomenclatura Brasileira, importante para corresponder às necessidades e o perfil da saúde das mulheres do Brasil. Este estudo é o ponto de partida para respaldar as práticas de consulta de enfermagem ginecológica com abordagens educativas, contemplando a população feminina em ações preventivas e incentivo ao tratamento.
\end{abstract}

Palavras-chave: História Natural. Neoplasias do Colo do Útero. Enfermagem Ginecológica. Saúde da Mulher.

\begin{abstract}
Study emerged from an article of the master degree that illustrates the phases of the historical evolution of the precursor lesions of the cervical-uterine cancer. Thus, it is a question of the history about, delineating the relevance of this knowledge for the nurse's practice in care in the woman's health. The precursor lesions concept of the cervical-uterine cancer, initiates itself from the XIX century, beginning with studies of the cells altered. It had as objective: describe the diverse historical phases of the cervical-uterine cancer. A qualitative, descriptive-analytical study, using time cutting in the period of 1940 to 2008. The data were raised by means of bibliographical reference as primary spring and about the resource BIREME, By means of this study was possible to score the different classifications that already existed, highlighting the Brazilian Nomenclature was important to correspond the needs and the profile of the health of the women of Brazil. This study is the starting point to support the gynecological nursing consultation practices with educational approaches, contemplating the female population in preventive actions and incentive to the treatment.
\end{abstract}

Keywords: Natural history. Uterine cervical neoplasms. Gynecological Nursing. Women's health.

\section{Resumen}

Estudio emergido de recorte de disertación de máster, ilustrando la evolución histórica de las lesiones precursoras del cáncer cervical-uterino (LPCCU). Se trata de la historia de las LPCCU, delineando la relevancia del conocimiento para la práctica del enfermero en cuidados en la salud de la mujer. El concepto de LPCCU se inicia a partir del siglo XIX, empezando los estudios de las células alteradas. Como objetivo: describir las diversas fases históricas de las alteraciones cervicales. Estudio cualitativo, descriptivo-analítico, recorte temporal en el período de 1940 hasta 2008. Datos acrecentados mediante bibliografía de fuente primaria y recurso BIREME. Se puntuó las diferentes clasificaciones que ya existieron, conde destaque para la nomenclatura brasileña, importante para corresponder a las necesidades y el perfil de la salud de las mujeres del Brasil. Esto estudio es el ponto de partida para respaldar las prácticas de consulta de enfermería ginecológica con abordajes educativas, contemplando la población femenina en acciones preventivas y incentivo al tratamiento.

Palabras Clave: Historia natural. Neoplasias del cuello uterino. Enfermería ginecológica. Salud de la mujer. 
Lesões precursoras e câncer cervical: evolução histórica.

\section{INTRODUÇÃO}

Historicamente, o útero foi representado como um símbolo feminino, principalmente pela sua função de reprodução e gestação que, por sua vez, levava a mulher ao seu papel socialmente esperado: 0 da maternidade. 0 cuidado com os problemas femininos pouco interessava aos médicos; no entanto, a fisiologia do corpo das mulheres despertava interesse no que tangia à reprodução. Desprovidas de recursos da medicina para combater as doenças femininas, as mulheres recorriam a curas informais, dotadas de suas fórmulas ancestrais, dos saberes sobre a utilização de plantas e ervas medicinais.

Contudo, a medicina foi tomando lugar e se posicionando, ampliando o seu conhecimento sobre as doenças ditas 'das mulheres'. Somente em meados do século XIX surgiu a ginecologia como uma especialidade médica. ${ }^{1}$ Assim, alguns ensaios terapêuticos para as doenças femininas, como investigações das células cervicais mediante microscópio, cirurgias para a retirada do útero, pólipos, amputação do colo uterino, aplicações medicamentosas, exames visuais, às vezes acompanhados por instrumentos invasivos, como o espéculo, foram surgindo como grande evolução no cuidado com esse corpo.

Diante desta premissa, surgiram descobertas e experimentos sobre o câncer do colo do útero e sua origem. No início, descobriu-se que antes do câncer propriamente dito apareciam lesões que modificavam as células do colo uterino, conhecidas como lesões pré-cancerosas. ${ }^{2}$

Neste sentido, a evolução do conceito de Lesões Precursoras do Câncer Cervicouterino (LPCCU) estabeleceuse desde o século XIX, quando ainda eram prevalentes os diagnósticos sombrios, seja pela precariedade de conhecimento anatômico-fisiológico, seja pela dificuldade sociocultural da mulher em se expor.

Porém, o entendimento da história natural do câncer cervical foi relevante para contribuir para a qualidade do tratamento dessas lesões que sofreram diversas modificações em suas terminologias ao longo do tempo, até os dias atuais. ${ }^{3}$ É importante sublinhar que a evolução do câncer do colo do útero incluiu várias fases que foram descritas por diversos estudiosos, desde a clássica categorização das alterações cervicais definidas por George Papanicolaou até a atual Nomenclatura Brasileira.

Diante destes pressupostos, este estudo teve como objetivo descrever as diversas fases da evolução dos conceitos das LPCCU, desde sua descoberta até a atualidade, inclusive trazendo à tona a Nova Nomenclatura Brasileira para Laudos Cervicais elaborada pelo Instituto Nacional do Câncer/Ministério da Saúde (INCA/MS). ${ }^{4}$

É importante ressaltar a relevância desse estudo, não só para o entendimento da evolução histórica das descobertas e classificações das lesões pré-cancerígenas, mas também para compreender que toda conduta preconizada foi pautada nessas diferentes classificações realizadas ao longo da história.

Mediante esses fatos, a prática da consulta de enfermagem ginecológica, no que tange à prevenção do câncer cervicouterino, deve basear-se nessa premissa, entendendo que o enfermeiro com conhecimento da evolução das alterações cervicouterinas, de sua classificação com as principais condutas indicadas para cada caso, é um grande aliado na luta contra os altos índices de morbimortalidade dessa patologia, que ainda hoje assola a mulher brasileira.

Neste sentido, conhecer os diversos conceitos das alterações cervicais, ao longo do tempo, salienta a importância de empenhos que ocorreram e vêm ocorrendo para que as terminologias associadas às neoplasias do trato anogenital inferior se tornem cada vez mais uniformes, assim como suas inferências clínicas, mais confiáveis.

\section{METOLOGIA}

Trata-se de um estudo pautado em uma revisão narrativa por permear o contexto da evolução das LPCCU, pois, de acordo com Rother ${ }^{5}$,os artigos que utilizam essa metodologia devem ser publicações próprias para discutir o assunto do ponto de vista teórico. A revisão constitui-se de análise da literatura publicada em livros e periódicos.

Os dados foram levantados mediante livros, teses e periódicos oriundos de biblioteca on-line da Bireme: LILACS e MEDLINE. Como descritores nacionais, utilizaram-se as palavrasexpressões: história das alterações cervicais, George Papanicolaou e câncer cervical, história do câncer cervical, história das lesões precursoras, eforam utilizados os descritores internacionais: natural history cervix; cervical cancer e history gynecologic, history of the precancerous cells. 0 espaço temporal estipulado dos artigos foi de 1940 a 2008. Este espaço temporal se justifica pela escassez de documentos de fonte primária que correspondessem, em anos anteriores, ao periódico encontrado no ano de 1942, já que 0 conceito de LPCCU inicia-se no século XIX. Vale ressaltar que os poucos artigos encontrados anteriormente ao ano de 1940 não trouxeram informações suficientes e pertinentes com o tema abordado, prevalecendo abordagens microscópicas e estudos laboratoriais.

Diante desse levantamento, foram encontrados, ao todo, 28 trabalhos, sendo 22 periódicos (17 internacionais e 5 nacionais), 5 livros e 1 tese, os quais subsidiaram a descrição da evolução histórica das alteraç̃ões cervicais do epitélio cervicouterino. Após leitura seletiva dos resumos, os artigos selecionados foram lidos na íntegra, permeando desde as primeiras definições das alterações cervicais até a terminologia atual das LPCCU. Obtiveramse 7 artigos que mencionaram a história de Papanicolaou e suas descobertas acerca do método de captação das células malignas por meio da citologia esfoliativa. Foram encontrados 5 artigos que tratam de estudos mais avançados acerca das células alteradas 
trazendo os termos displasia e Neoplasia Intraepitelial Cervical (NIC) propostos por Reagan e Richart, respectivamente; 4 artigos mencionam as principais terminologias impostas pelo Sistema de Bethesda, com suas importantes modificações; e os periódicos restantes trazem estudos que mencionaram as correlações dos termos propostos por estudiosos, além da avaliação dos diversos conceitos e terminologias e a atual nomenclatura brasileira. Por fim, elaborou-se um quadro ilustrando a evolução histórica das terminologias das LPCCU correspondentes ao período de 1940 a 2008 (Quadro 1).

Quadro 1-Evolução histórica das lesões precursoras do câncer cervicouterino

\begin{tabular}{|c|c|c|c|c|c|c|}
\hline $\begin{array}{c}\text { Papanicola } \\
\text { ou } \\
1941\end{array}$ & $\begin{array}{l}\text { Reagan } \\
1956\end{array}$ & $\begin{array}{l}\text { Richart } \\
1968\end{array}$ & $\begin{array}{l}\text { Richart } \\
1990\end{array}$ & $\begin{array}{c}\text { Bethesda } \\
1988 \text { - } \\
1991\end{array}$ & $\begin{array}{l}\text { Bethesda } \\
2001\end{array}$ & $\begin{array}{c}\text { Nomenclatura } \\
\text { Brasileira } \\
2006\end{array}$ \\
\hline Classe I & Normal & Normal & Normal & $\begin{array}{l}\text { Alterações } \\
\text { celulares } \\
\text { benignas }\end{array}$ & $\begin{array}{l}\text { Negativo para } \\
\text { lesões } \\
\text { intraepiteliais } \\
\text { ou malignidade }\end{array}$ & $\begin{array}{l}\text { Alterações } \\
\text { celulares } \\
\text { benignas }\end{array}$ \\
\hline \multirow{3}{*}{ Classe II } & \multirow{3}{*}{ Atipias } & \multirow{3}{*}{ Atipias } & \multirow{3}{*}{ Atipias } & & \multirow{3}{*}{$\begin{array}{l}\text { ASC-US: } \\
\text { ASC-H: }\end{array}$} & $\begin{array}{r}\text { ASC-US } \\
\text { ASC-H } \\
\end{array}$ \\
\hline & & & & ASCUS & & $\begin{array}{l}\text { Atipias de significado } \\
\text { interterminado de } \\
\text { origem indefinida: }\end{array}$ \\
\hline & & & & AGUS & & $\begin{array}{l}\text { Possivelmente não } \\
\text { neoplásica, } \\
\text { não podendo afastar } \\
\text { HSIL de alto grau }\end{array}$ \\
\hline \multirow{3}{*}{ Classe III } & $\begin{array}{l}\text { Displasia } \\
\text { Leve } \\
\end{array}$ & NIC I & $\begin{array}{l}\text { NIC I/HPV } \\
\text { Baixo grau } \\
\end{array}$ & LSIL & LSIL & LSIL \\
\hline & $\begin{array}{l}\text { Displasia } \\
\text { Moderada }\end{array}$ & NIC II & NIC II & \multirow[b]{2}{*}{ HSIL } & \multirow[b]{2}{*}{ HSIL } & \multirow[b]{2}{*}{ HSIL } \\
\hline & $\begin{array}{l}\text { Displasia } \\
\text { acentuada }\end{array}$ & NIC III & $\begin{array}{c}\text { NIC III } \\
\text { Alto grau } \\
\text { Carcinoma } \\
\text { in situ } \\
\end{array}$ & & & \\
\hline Classe IV & $\begin{array}{l}\text { Carcinoma } \\
\text { in situ }\end{array}$ & $\begin{array}{l}\text { Carcinoma } \\
\text { in situ }\end{array}$ & & & & $\begin{array}{l}\text { HSIL, não podendo } \\
\text { excluir microinvasão }\end{array}$ \\
\hline \multirow{2}{*}{ Classe V } & $\begin{array}{l}\text { Carcinoma } \\
\text { escamoso } \\
\text { invasor }\end{array}$ & $\begin{array}{l}\text { Carcinoma } \\
\text { escamoso } \\
\text { invasor }\end{array}$ & $\begin{array}{c}\text { Carcinoma } \\
\text { escamoso invasor }\end{array}$ & $\begin{array}{l}\text { Carcinoma } \\
\text { invasor de } \\
\text { células } \\
\text { escamosas }\end{array}$ & $\begin{array}{c}\text { Carcinoma de } \\
\text { células escamosas }\end{array}$ & $\begin{array}{l}\text { Carcinoma } \\
\text { epidermoide invasor }\end{array}$ \\
\hline & $\begin{array}{c}\text { Adenocarcino } \\
\text { ma }\end{array}$ & $\begin{array}{c}\text { Adenocarcino } \\
\text { ma }\end{array}$ & Adenocarcinoma & $\begin{array}{l}\text { Adenocarc } \\
\text { inoma } \\
\text { invasor }\end{array}$ & $\begin{array}{c}\text { Adeno } \\
\text { carcinoma in } \\
\text { situ } \\
\text { Adenocarcinoma } \\
\text { invasor }\end{array}$ & $\begin{array}{c}\text { Adenocarcinoma in } \\
\text { situ } \\
\text { Adenocarcinoma } \\
\text { invasor }\end{array}$ \\
\hline
\end{tabular}

Fonte: Carvalho e Queiroz (2007)

Legenda: NIC - Neoplasia intraepitelial cervical, ASCUS - Atipias de significado indeterminado em células escamosas, AGUS - Atipias de significado indeterminado em células glandulares, ASC-US - Atípicas de células escamosas de significado indeterminado, possivelmente não neoplásicas, ASC-H - Atípicas de células escamosas de significado indeterminado, não podendo afastar lesão de alto grau, HSIL Lesão intraepitelial escamosa de alto grau, LSIL - lesão intraepitelial escamosa de baixo grau.

\section{AS LPCCU:UM PANORAMA DA EVOLUÇÃO DOS CONCEITOS}

Nos últimos 60 anos, a compreensão da etiologia e patogenia da neoplasia escamosa do trato genital inferior aumentou, principalmente com o progresso dos eventos moleculares associados a essa patologia. Em resposta aos novos conhecimentos, a terminologia também mudou, originando a cada descoberta um novo sistema de classificação, que refletia o pensamento científico da época e, consequentemente, uma conduta terapêutica própria.

Em se tratando do conceito de células cervicais prémalignas, Williams, em 1888, foi o primeiro aidentificar que próximo das áreas cancerígenas havia também células não invadidas pelo câncer. Mas foi somente Cullen, em 1900, que melhor definiu essas lesões não invasoras, trazendo então o conceito de "precursor do câncer", o qual tornou-se mais aceito nos meios científicos. Esta descoberta foi importante, pois proporcionou a revelação de uma fase pré-maligna anterior, podendo ser entendido que as alterações precursoras tinham alta possibilidade de desenvolvimento para o câncer, se não tratadas a tempo. ${ }^{6}$ Esses tratamentos eram incipientes, baseando-se em histerectomias radicais, já que pouco se conhecia a respeito do processo contínuo de mudança das células alteradas.

0 termo carcinoma in situ (CIS) foi dado 32 anos após a definição de Cullen, por outro estudioso, Brothers. Esse termo foi introduzido para indicar que as lesões precursoras ocupavam todo o tecido do epitélio, porém não rompiam a camada basal; ou seja, ainda não se tratava de um câncer invasivo. ${ }^{7}$ Deve-se destacar que o colo do útero é revestido por várias camadas de células epiteliais de forma ordenada, e a desordenação de todas as camadas foi denominada CIS. ${ }^{8}$ Vale mencionar que esse termo não é mais considerado pelas terminologias atuais, apesar de ainda hoje encontrarmos alguns profissionais que erroneamente utilizam essa denominação. Já o termo carcinoma invasor de células escamosas 
Lesões precursoras e câncer cervical: evolução histórica.

foi dado mediante combinações de observações histológicas, revisões retrospectivas em biópsias e análise clínica, o que leva a concluir que as alterações celulares do epitélio já ultrapassaram a camada basal, invadindo o estroma.

Esse termo ainda hoje é atualizado para indicar a gravidade de invasão celular, porém, comparando-se o que era utilizado na época com o que é empregado contemporaneamente, se difere, principalmente, pelo conhecimento do processo de continuidade das alteraç̧ões das células cervicais, ou seja, a fase inicial da modificação cervicocelular até a fase invasiva.

Os tratamentos empregados também se diferem, visto que o curso clínico destas alterações ainda não era bem compreendido. A possibilidade de uma célula cervical, inicialmente alterada, prosseguir para o desenvolvimento de uma célula maligna era ignorada, por isso mantinha-se como terapêutica indicada a histerectomia radical.

0 entendimento era de que essas alterações cervicais evidenciavam o desenvolvimento para o câncer, e consequentemente para a morte feminina. Assim, quanto antes fosse retirado totalmente o útero, com esvaziamento pélvico, se poderia melhorar a sobrevida da mulher. Percebe-se, então, que o que era entendido como lesões precursoras na verdade tinha uma alta probabilidade de evoluir para uma doença grave, ou seja, era como uma sentença de morte, caso o útero não fosse retirado imediatamente.

Esta atitude fez com que muitas mulheres perdessem 0 útero, ainda jovens e em plena fase reprodutiva, e houve muitas mortes pelas complicações cirúrgicas. Vale a pena mencionar que uma mulher naquela época, sem sua matriz - como o útero era chamado - era uma mulher inútil e estragada socialmente ${ }^{9}$, o que levou muitas mulheres e seus maridos a não aderirem a esse tipo de tratamento. Este fato ilustra a representação da fragilidade feminina, principalmente pelo seu desequilíbrio proveniente da matriz, ou seja, do útero.

\section{O MARCO NA HISTÓRIA GINECOLÓGICA: A ERA PAPANICOLAU}

Geórgio Papanicolau foi um médico grego que dedicou sua vida aos estudos sobre a citologia vaginal e da cérvice. Em 1917, Papanicolaou descobriu como ocorria o processo de ovulação. Este fato levou-o a descobrir que existiam variações de padrões e sequências citológicas diferentes que determinavam o ciclo ovariano e menstrual. .011 $^{10-1}$

Por volta de 1920, elaborou uma técnica para estudar as células vaginais e do colo uterino, conhecida como método de citologia esfoliativa, técnica utilizada até os dias atuais no combate ao câncer de colo uterino. Este estudioso iniciou as coletas citológicas em sua esposa, pois, como se sabe, as mulheres, à época, eram restritas ao lar, eram tidas como incapazes para a sexualidade e apenas tinham a função de maternar e serem esposas; por isso, seus corpos não deveriam ser expostos em nenhuma hipótese. ${ }^{1}$ Somente com o passar do tempo, Papanicolaou conseguiu realizar exames em algumas grávidas e pós-menopáusicas, podendo, então, definir o ciclo sexual da mulher por esfregaços vaginais e do colo.

Após 3 anos de estudos, em 1923, Papanicoloau sugeriu o uso de seu método de citologia esfoliativa para o diagnóstico de câncer cervicouterino (CCU) em todas as mulheres. Contudo, apesar de se tratar de um método mais fácil e de maior amplitude, a sua ideia não foi aceita, por preconceito e temor da exposição feminina. 0 método utilizado na época era a biópsia, mas somente em ditos casos "suspeitos".

Mesmo assim, este cientista continuou suas investigações dando início, em 1925, a um estudo com mulheres voluntárias e trabalhadoras de um hospital de Nova York. Dotado de experiência na observação da diferenciação dos esfregaços, coincidentemente realizou este procedimento em uma mulher com CCU, na qual encontrou células alteradas, sendo assim, a primeira observação de células cancerosas em secreções da cérvice. ${ }^{10}$ Para confirmar suas observações, decidiu realizar a citologia esfoliativa em todas as mulheres atendidas em um serviço de ginecologia, tendo como resultado um considerável número de casos com diagnóstico de neoplasias cervicouterinas. Isso permitiu verificar as alterações celulares em fases tão iniciais que eram invisíveis a uma simples inspeção ocular, só possível mediante visualização no microscópio. ${ }^{12}$

Assim, sua técnica passou a ser considerada uma excelente ferramenta para a detecção precoce do câncer cervical, surgindo o conceito de detecção precoce como conhecemos hoje em dia, ou seja, esse exame, tido como preventivo, é realizado com o intuito de identificar, o mais cedo possivel, alterações celulares que podem evoluir para o câncer de colo do útero.

Este grande descobrimento foi um marco na história ginecológica, pois veio a proporcionar um procedimento menos invasivo e traumatizante para as mulheres, pois até então o exame preconizado era somente a biópsia que já era realizada em estágios avançados da doença. Vale mencionar que todos esses estudos ocorreram diante de fortes resistências sociais, seja por parte das mulheres, que nem sempre eram cooperativas e recusavam-se a fazer esse tipo de exame pela exposição do corpo, seja pela proibição de seus pais ou maridos, que não aceitavam a ideia de "suas mulheres" exporem seus órgãos genitais a médicos-homens, algo que, infelizmente, ainda está presente até os dias atuais. A submissão feminina, histórica e culturalmente, ainda é nítida em nossos dias, quando algumas mulheres deixam de realizar seu exame preventivo por "ordem" de seus parceiros.

Outra barreira que a citologia esfoliativa de Papanicolaou enfrentou foi a da Igreja, que acreditava que 0 exame era uma forma profana e demoníaca de exposição do corpo feminino. Desse modo, além de ser desconhecido o real motivo do exame, havia o receio de que as mulheres pudessem ser usadas para experiências científicas e ficarem "mal-faladas" 
pela sociedade. ${ }^{1}$ Mesmo diante de todas essas adversidades encontradas, Papanicolaou com seu exame citológico conseguiu que a mortalidade por câncer cervicouterino caísse em torno de $10 \%$ em poucos anos entre a população que era submetida a esse procedimento. ${ }^{13}$ Assim, passou-se a preconizar como rotina a citologia esfoliativa para todas as mulheres, mesmo as assintomáticas. 0 procedimento passou a ser conhecido como Exame de Papanicolaou.

Em 1941, perante a variedade de epitélios atípicos encontrados na cérvice, Papanicolaou elabora a primeira classificação dessas alterações, criando uma nomenclatura que procurava expressar se as células observadas eram normais ou não. A lesões foram assim classificadas: Classe I indicava a ausência de células atípicas ou anormais; Classe II designava citologia atípica, mas sem evidência de malignidade; Classe III apontava citologia sugestiva, mas não conclusiva, de malignidade; Classe IV determinava citologia fortemente sugestiva de malignidade e, finalmente, a Classe V que indicava citologia conclusiva de malignidade. ${ }^{4}$

Sem dúvida, esta primeira classificação ajudou a determinar aquelas mulheres que apresentavam possibilidades de desenvolver - CCU e atuar precocemente antes de sua evolução, mesmo diante dos parcos tratamentos da época que ainda eram muito invasivose radicais, como as histerectomias. No entanto, iniciou-se um melhor critério para submeter a mulher à retirada do útero, assim como foram desenvolvidas técnicas cirúrgicas menos manipuladoras, como as histerectomias parciais. Vale ressaltar que a citologia esfoliativa dePapanicolaou trouxe, para a mulher, melhores expectativas acerca da sua feminilidade, já que a histerectomia está, muitas das vezes, atrelada a sentimentos como o fim da reprodução e maternidade. ${ }^{14}$

No Brasil, o exame Papanicolaou foi introduzido na década de 50 , com as mesmas dificuldades culturais e sociais que em outros países. Mas acreditamos que esta década, por ter sido uma época entre o período de guerras da primeira metade do século XX e o período de revoluções comportamentais e tecnológicas, como televisão, pesquisas, descobertas científicas, crescimento industrial, além do destaque da indústria farmacêutica e equipamentos hospitalares, sem contar com a grande revolução sanitária, propiciou a introdução desse exame, tendo uma certa aderência das mulheres e da sociedade como um todo.

\section{NOVAS CLASSIFICACÕES ACERCA DAS LPCCU}

As pesquisas continuaram e a citologia foi se aperfeiçoando, trazendo cada vez mais credibilidade às mulheres, principalmente por provar que detectando as alterações cervicais pré-invasivas as chances de sobrevida eram maiores, mesmo sem o útero.

Dando continuidade às investigações acerca das LPCCU, em 1956, Dr. James W. Reagan reconheceu a importância em estabelecer a ocorrência das alterações cervicais e definiu o termo "displasia" para designar anormalidades intermediárias entre o epitélio normal e 0 CIS, tanto em exames histológicos como nos citológicos. ${ }^{9}$ Esse termo passou, então, a ser utilizado referindo-se às células alteradas, localizadas na superfície do epitélio e que podiam ser detectadas através de raspagem de amostras desta superfície e observação ao microscópio. ${ }^{7}$

É importante ressaltar que se denominou displasia por tratar-se de um processo de lesão pré-neoplásica. Esta fase foi considerada uma forma de proliferação celular que ocorre nas células epiteliais. Através do acompanhamento desses estudos, observou-se que um tecido com frequente ocorrência de lesões poderia regredir ou progredir para a doença, ou seja, o câncer em si, mostrando aqui uma nova faceta, até então desconhecida, de evolução ou involução. Este termo introduzido no final dos anos 50 permitiu, também, estabelecer critérios de maior rigorosidade científica para o diagnóstico citológico.

Com essa nova conclusão, Reagan estabeleceu e organizou uma nova categorização, subclassificando as displasias em três grupos: Displasia Leve, Moderada e Severa. Essa classificação baseava-se na quantidade de espessura do epitélio que apresentava células neoplásicas, ressaltando que quanto maior o grau histológico, maior a probabilidade de a lesão progredir para um carcinoma invasor. Neste contexto, essa classificação mais minuciosa assumiu o lugar do sistema popular de categorização de Papanicolaou.

Ressalta-se que muitos outros termos foram propostos, mas não foram muito aceitos pelo público científico. A popularidade da nomenclatura displasia/ carcinoma in situ tornou-se a terminologia dominante. ${ }^{2}$

Com relação às condutas terapêuticas, o que passou a vigorar é que as mulheres com diagnóstico de displasia severa e CIS eram as eleitas para as cirurgias de histerectomias, enquanto que as outras eram ignoradas, ou cada médico teria uma estratégia diferente, não tendo um consenso quanto aos procedimentos, principalmente por não se conhecer quando aconteceria a remissão, a persistência ou a progressão da doença.

\section{A TERMINOLOGIA DE RICHART E A PRESENÇA DO HPV}

Passados os anos e mediante vários estudos, chegou-se à conclusão de que os termos displasia e CIS eram considerados definições errôneas, já que existia uma continuidade de mudanças celulares, além de uma correlação entre progressão e grau das lesões. Assim, essas terminologias passaram a ser arbitrárias e superficiais, levando a diferentes abordagens de tratamento sem consistência devido à falta de confiabilidade dos diagnósticos, apesar de, ainda hoje, ser observada, na prática da enfermagem ginecológica, a ampla utilização desses termos. 
Lesões precursoras e câncer cervical: evolução histórica.

Contudo, em 1968, Richart propôs uma nova terminologia com o propósito de melhor definir a biologia e a história natural das lesões específicas do colo uterino, referidas até então como displasias, termo que era utilizado para qualquer tecido do corpo que apresentasse as alterações típicas. Esta nova terminologia foi universalmente denominada Neoplasia Intraepitelial Cervical (NIC) para indicar uma gama de atipias celulares limitadas ao epitélio do colo do útero. Esta foi dividida em graus I, II e III. A NIC I correspondia à displasia leve, quando acometia um terço do epitélio; NIC II, à displasia moderada, quando acometia dois terços do epitélio; e NIC III, quando já agredia três terços do epitélio. Vale mencionar que Richart englobou no termo NIC III a denominação carcinoma in situ. ${ }^{15}$

Com a expansão da tecnologia molecular nos estudos das lesões do colo uterino no final dos anos 70, identificouse a forte presença do Papiloma Vírus Humano/HPV nessas lesões, que eram suspeitas de Doenças Sexualmente Transmissíveis/DST desde a antiguidade. No entanto, em 1978, foi descrita a coilocitose, como efeito citopático do HPV, reconhecendo que as infecções por HPV eram, frequentemente, associadas à NIC. ${ }^{2}$ Esse achado levou a confusões nas nomenclaturas utilizadas, pois surgiu uma proliferação de termos, como condiloma achatado, condiloma plano, atipia verrucosa para designar a presença do vírus. Apesar dessa confusão, uma certeza os estudiosos tinham: a presença do HPV nas lesões intraepiteliais, ficando este como principal agente etiológico para o CCU.

\section{A CLASSIFICAÇÃO DE BETHESDA}

Diante dsses novos achados, principalmente da forte ligação entre HPV e os NIC, no ano de 1988, um grupo de estudiosos reunido no Instituto Nacional do Câncer dos Estados Unidos, em um simpósio em Bethesda/Maryland, introduziu uma nova terminologia para a citologia, que ficou conhecida como o Sistema de Bethesda/TBS. ${ }^{16}$ Este sistema teve duas revisões nos anos de 1991 e 2001, procurando uniformizar as terminologias, assim como as condutas para cada classificação.

Inicialmente, introduziram-se as terminologias Atipias de Células Escamosas de Significado Indeterminado (ASCUS) e Atipias Glandulares de Significado Indeterminado (AGUS). No entanto, esta classificação não foi suficiente para realizar o diagnóstico da lesão, além de não distinguir o HPV. Neste contexto, o TBS teve sua primeira revisão, em 1991, baseada nos pressupostos de Richart que, em 1990, propôs uma racionalização da terminologia das alterações anatomopatológicas associadas à infecção pelo HPV, levando a nomenclatura para apenas dois graus.

Destarte, esta revisão incluiu a infecção do HPV em função do risco evolutivo e alterou a terminologia Neoplasia
Intraepitelial Cervical/NIC para Lesão Intraepitelial/LIE. Isso se deu pelo fato de que o termo NIC já classificava como neoplasia uma entidade que, na maioria das vezes, regredia espontaneamente, podendo acontecer mesmo sem tratamento específico. Portanto, o termo "lesão" substituiu o termo "neoplasia", visto que a associação de quaisquer graus morfológicos da alteração celular não necessariamente identifica um processo neoplásico.

Assim, distinguiram-se dois grupos de LIE: uma de baixo grau (LSIL), que correspondia ao NIC I, e as associações celulares ligadas ao HPV com as LIE de alto grau (HSIL), que correspondiam aos NIC II e NIC III, essas duas últimas consideradas como genuinamente precursoras da neoplasia invasiva. No entanto, as categorias ASCUS e AGUS continuaram.

Esta revisão do TBS foi muito enriquecedora, pois determinou uma estratégia para a redução do tipo de câncer pelo controle das DST em que está inserida a infecção pelo HPV. Começa-se a entender a importância de se prevenir 0 câncer cervicouterino através da prevenção de DST, como o uso de preservativo em todas as relações, a diminuição de parceiros sexuais e tratar as afecções ginecológicas, dentre outros.

Vale apenas destacar que o adenocarcinoma in situ foi a única lesão glandular intraepitelial claramente caracterizada, também associada ao HPV de alto risco; também foi descoberto que era menos frequente que as lesões escamosas, porém mais agressivas. Desta forma, as mulheres com esse diagnóstico eram submetidas a histerectomias radicais com esvaziamento pélvico. Conduta que até hoje é preconizada.

Com a continuação dos estudos entre o HPV e o CCU, começou-se a perceber outras circunstâncias também consideradas fundamentais para o desenvolvimento das LPCCU e consequentemente do câncer, como as baixas condições socioeconômicas, a multiplicidade de parceiros e o início cada vez mais precoce das atividades sexuais femininas, a AIDS, o uso indiscriminado de anticoncepcionais hormonais e, principalmente, o tabagismo. Ou seja, verificouse que existia uma série de aspectos socioeconômicos e culturais que levavam a uma predisposição à evolução do HPV ao CCU, surgindo a denominação de cofatores de risco e os aspectos de vulnerabilidade feminina.

Assim, novamente no ano de 2001, com a participação de outros países, inclusive o Brasil, ${ }^{16}$ o Instituto Nacional do Câncer dos Estados Unidos realizou um novo simpósio para propor um novo esquema de registro dos resultados da citologia cervical. Esta foi a última revisão do TBS que não modificou os critérios morfológicos, mas trouxe a proposta de mudança na interpretação e nova divisão.

Foram então modificadas as categorias AGUS e ASCUS. Esta última passou a ser dividida em duas categorias: atipias de células escamosas (ASC) de significado indeterminado, possivelmente não neoplásico (ASC-US), e atipias em células escamosas de significado indeterminado, 
em que não se pode afastar lesão de alto grau (ASC-H), sendo a denominação AGUS eliminada. ${ }^{4}$

No sistema antigo, todas as células da categoria ASCUS eram consideradas, equivocadamente, atípicas, mas não especificamente pré-cancerosas. 0 novo sistema adicionou a categoria atipias de células escamosas não podendo excluir lesões de alto grau (ASC-H), facilitando a diferenciação entre as lesões que podem ou não ser de origem neoplásica.

As recomendações deste simpósio estabeleceramse como critério internacional de padronização dos diagnósticos citopatológicos até os dias atuais. ${ }^{17}$ No entanto, deve-se considerar que a classificação de Bethesda com suas revisões foi um dos marcos importantes no conceito das LPCCU, trazendo terminologias mais específicas e podendo, assim, nortear o profissional de saúde para um diagnóstico mais preciso.

\section{A NOMECLATURA BRASILEIRA}

Associação Brasileira de Genitoscopia referiu que o sistema de classificação Bethesda atende às necessidades primordialmente norte-americanas, não contemplando as reais necessidades dos demais países, indicando a impossibilidade de haver uma linguagem única para todo o mundo. Neste sentido, entendeu-se que era imprescindível que houvesse uma adequação de informação para o examinador e para a cliente no sentido de subsidiar a conduta a ser realizada. Fortalecendo essa premissa, o Brasil, em 2006, elabora e lança a Nomenclatura Brasileira para Laudos Cervicais e Condutas Preconizadas, que estabelece uma classificação própria para o país, levando em conta suas características e a epidemiologia brasileira. ${ }^{4}$

A nomenclatura brasileira inseriu novas terminologias, tais como a criação de uma categoria distinta para todas as atipias de significado indeterminado e ainda a categoria "origem indefinida", que se refere àquelas situações em que não se pode estabelecer com clareza a origem da célula atípica. A expressão "provavelmente reativa" foi substituída pela expressão "possivelmente não neoplásica" e introduziu a expressão "não se pode afastar lesão intraepitelial de alto grau". Foram excluídas as terminologias ASCUS e AGUS, como recomendadas pelo Sistema de Bethesda, porém foi adotado o termo "lesão intraepitelial" em substituição a "neoplasia intra-epitelial". Essas alterações se devem ao fato da importância em intensificar a verdade biológica das mudanças progressivas passo-a-passo da evolução cancerosa e abolir algumas das dificuldades práticas em compreender estes eventos patológicos.

Com relação às condutas preconizadas para 0 acompanhamento, tratamento e seguimento das mulheres brasileiras, o documento da Nomenclatura Brasileira orienta que estes devem ser realizados de acordo com o grau de complexidade de cada unidade de saúde, ou seja, em conformidade com o nosso Sistema Único de Saúde: o SUS. Essas diretrizes visam orientar os profissionais de saúde com relação às condutas indicadas, inclusive organizando a rede de serviço de saúde conforme o nível de complexidade de cada um.

Em se tratando do primeiro nível de atenção básica, este deve ter a responsabilidade de iniciar o processo de assistência, em que a mulher deve ser submetida à citologia de rastreamento e controle citológico. Já uma unidade secundária deve ser referência para o serviço de patologia cervical, que tem a função de confirmação diagnóstica, tratamento e acompanhamento das alterações pré-malignas ou malignas. Nesta fase, acontece o controle citopatológico, colposcópico, biópsia e métodos excisionais, como a Cirurgia de Alta Frequência /CAF.

Por último, como terceiro nível de atenção à saúde, temos a unidade terciária, onde devem ocorrer procedimentos de alta complexidade como cirurgias, conizações, histerectomias, ooforectomias, radioterapia e quimioterapia.

É importante sublinhar que a rotina de rastreamento citológico deve ser realizada nas unidades básica de saúde, preferencialmente dentro da Estratégia da Saúde da Família, para maior controle e seguimento das mulheres, atividade que vem sendo realizada pelo enfermeiro. No entanto, é fundamental que este profissional saiba não só ter uma técnica de coleta adequada, mas também interpretar um laudo citológico, reconhecendo a classificação. Todo esse processo é de fundamental relevância. Sabemos hoje que se 0 profissional, que está na unidade básica, não tiver uma conduta adequada a cada classificação das LPCCU, poderá haver evolução para câncer do colo do útero. Neste sentido, é também relevante incentivar a busca ativa quando algumas mulheres, após realizarem o exame de Papanicolaou, não retornam para buscar seus resultados. ${ }^{18}$

Apesar de a evolução dessa patologia ser lenta, podendo até mesmo estagnar ou regredir, cerca de $40 \%$ dos casos evoluirão no período de 10 anos para o câncer invasivo. ${ }^{19}$ No entanto, vale salientar que a chance de cura é de $100 \%$ quando realizado tratamento adequado e no tempo certo. ${ }^{7}$ Acrescenta-se, ainda, que as lesões de baixo grau são muito frequentes e não oferecem riscos, desaparecendo, às vezes, mesmo sem tratamento na maioria das mulheres, o que é denominado de regressão espontânea ou de clearence, diferente das lesões de alto grau, que apresentam risco relevante de progredirem para câncer caso não haja intervenção. 
Lesões precursoras e câncer cervical: evolução histórica.

\section{CONCLUSÕES}

Sabe-seque, devido àmelhor compreensão sobre os estudos moleculares associados às patologias do trato anogenital inferior, houve uma mudança da terminologia, apresentando novos sistemas de classificação. No entanto, se essas mudanças não forem compreendidas e introjetadas pelos profissionais de saúde, haverá maiores chances de divergências de condutas, erros de diagnósticos e procedimentos inadequados, fatos que podem levar ao aumento da incidência de câncer cervical. Este entendimento é um subsídio para uma melhor atuação, seja na consulta de enfermagem ginecológica, no serviço de patologia cervical ou no atendimento de alta complexidade em oncologia.

É importante ainda que seja cada dia mais divulgada a Nomenclatura Brasileira para Laudos Cervicais e Condutas Preconizadas para que efetivamente esta seja implementada em todos os níveis de saúde e assim tenhamos uma única classificação uniforme, algo que hoje em dia ainda não é efetivo em nosso país. Não que não necessitemos de novas pesquisas que fomentem e deem continuidade a estudos que avaliem processos patológicos do desenvolvimento das LPCCU e a sua evolução conceitual, mas se faz urgente que a Nomenclatura Brasileira seja reconhecida e colocada em prática.

Por fim, a atuação do enfermeiro, nesta área, deverá ser sempre subsidiada por conhecimento alicerçado em suportes teóricos acerca das lesões precursoras e sua evolução histórica para que se possa oferecer um cuidado para estas mulheres de forma segura e profícua, excluindo e reduzindo a possibilidade de morbidade por DST e, como consequência, a maior probabilidade para o desenvolvimento do câncer do colo do útero.

\section{REFERÊNCIAS}

1.Martins APV. Visões do feminino: a medicina da mulher nos séculos XIXe XX. Rio de Janeiro: FIOCRUZ; 2004. [Coleção História e Saúde]

2.Sellors JW. Colposcopia e tratamento da neoplasia intra-epitelial cervical: Manual para participantes. Washington, D.C: OPAS; 2004.

3. Holowaty P, Miller AB, Teresa TR. Natural history of dysplasia of the uterine cervix. Reports. J National Cancer Institute 1999 Feb; 91 (3).252-57.

4.Ministério da Saúde (BR). Instituto Nacional de Câncer. Coordenação de Prevenção e Vigilância. Nomenclatura brasileira para laudos cervicais e condutas preconizadas: recomendações para profissionais de saúde. $2^{\mathrm{a}}$ ed. Rio de Janeiro (R); 2006.

5.Rother ET.Revisão sistemática x revisão narrativa.Acta Paul Enferm 2007abr/jun; 20(2).

6. Richart R, Wright TC. A histologia da neoplasia do trato anogenital inferior. In: Singer A, Monoghan J. Colposcopia, patologia e tratamento do trato genital inferior. Porto Alegre(RS): Artes Médicas; 1995

7.Bonfiglio TA. History of gynecologic pathology. Int I Gynecol Pathol 2003 jan; 22(1): 95-100.
8.Friedell GH. Carcinoma, carcinoma in situ, and ,"erly lesions" of the uterine cervix and the urinary bladder: introduction and definitions. Cancer Research. 1976 july; 36(1): 2482-2484.

9.Tubert $\mathrm{S}$. Mulheres sem sombra maternidade e novas tecnologias reprodutivas. Rio de Janeiro (RJ): Rosa dos Tempos; 1996.

10.Garcia OFD. Historia de George Papanicoloau y de La tinción que lleva su nombre. Elementos 2005 abr/jun; 58(12): 19-26.

11.Romero N. Reseña histórica de la citopatología y los orígenes del Papanicolaou. Anales de la Facultad de Medicina; 2001 mayo. 3-5; Lima, Perú. Lima: Universidad Nacional Mayor de San Marcos; 2000. p. 342-346.

12.Bravastro G, George N. Papanicolaou. Maestro, pioneiro, sábio. [on line].2000 [citado 5 ago 2007]. Disponivel em: http://www.gineconet.com/ artículos/457.htm

13..Papanicolaou GN. A new procedure for staining vaginal smears. Science 1942: 95(2469): 438-40.

14..Salimena AMO, Souza IEO. 0 sentido da sexualidade de mulheres submetidas a histerectomia: uma contribuição da enfermagem para a integralidade da assistência ginecológica. Esc Anna Nery Rev Enferm 2008; 12 (4): 645-50.

15..Bueno KS. Atipias escamosas de significado indeterminado: novas qualificações e importância na conduta clínica. RBAC. 2008; 40(2): $121-28$.

16..Broso PR, Buffetti G.The Papanicolaou classification in the Bethesda System. (National Cancer Institute, Bethesda, Maryland). Minerva Ginecol. 1993 Nov; 45(11): 557-63.

17.Bergeron C.The 2001 Bethesda System. Salud Pública de México 2003; 45 (Suppl 3)

18.Carvalho MCP, Queiroz ABA. Absenteísmo do resultado do preventivo do câncer cérvico-uterino alterado de um CMS do Rio de Janeiro: um estudo do perfil epidemiológico dessas mulheres. In: Anais do $5^{\circ} \mathrm{COBEON}$; 2007 out 14-17; Bento Gonçalves (RS), Brasil. Bento Gonçalves (RS): ABENF0;2007

19.Ministério da Saúde (BR). Secretaria de Atenção à Saúde. Departamento de Atenção Básica. Controle dos cânceres do colo do útero e da mama.. Brasilia (DF); 2006. [Caderno de Atenção Básica, 13]

\section{NOTA}

a Este trabalho foi premiado em $3^{\circ}$ lugar no evento: $1^{\circ}$ Encontro de Enfermagem ginecológica do Estado do Rio de Janeiro para publicação na Revista da Escola de Enfermagem Anna Nery-EEAN/UFRJ. 